\title{
Review
}

\section{Connected by commitment: Oppression and our obligation to undermine it}

\author{
Mara Marin \\ Oxford, Oxford University Press, 2017, x+2216pp, \\ ISBN: 978-0190498627
}

Contemporary Political Theory (2019) 18, S175-S178. https://doi.org/10.1057/s41296018-0221-8; published online 25 April 2018

Structural oppression presents a vexing problem for those concerned with justice. Political and normative action is often understood in terms of intention. But structures are large and impersonal. They exceed individual control, and operate in ways that many people would rather they did not. Yet the fact that injustice is structural rather than the product of our intentions, Mara Marin argues, cannot let us off the hook for addressing it: our actions are shaped by unjust structures, and our actions also perpetuate them, whether or not we want them to. We cannot extricate ourselves from unjust structures entirely, and we should not pretend otherwise. But nor can we shrug at structural constraints and abdicate our own role in reproducing them. Unjust structures are not external to our actions, but constituted by them.

What, though, can we do? Our individual actions seem powerless against deeply ingrained prejudices and socially entrenched power structures - so much so that we may throw up our hands altogether, declaring oppression beyond our ability to resolve, and therefore not our responsibility to address. These two challenges mutually reinforce one another, creating a 'circle of powerlessness and denial' ( $p$. 1) in which we get trapped when we consider the paradox of our obligation to address oppression and the apparent impossibility of doing so.

To break the cycle, Marin proposes the notion of commitment. Commitments are 'relationships of obligations that develop over time, through the long-term open-ended responsive action between two or more persons' (p. 3). Marriages, families, and friendships are examples of personal commitments, each coming with specific norms and obligations; Marin wants to use these kinds of relationships to model an approach to understanding social ones. Just as we have obligations to friends and family members with whom we have personal relationships, we also have obligations to people to whom we are connected as a result of impersonal social structures.

(c) 2018 Macmillan Publishers Ltd., part of Springer Nature. 1470-8914 Contemporary Political Theory Vol. 18, S3, S175-S178 www.palgrave.com/journals 
In particular, because we contribute to oppressive structures through our actions, we have the obligation to undo oppression by making 'whatever changes are necessary' (p. 62). Addressing oppression, Marin recognizes, requires not individual but collective action - action that is cumulative and constituted by 'chains of action and response' (p. 52). We act, and others respond to our actions, as we do to theirs. We thus build new relationships that come with new obligations.

Crucially, although commitments are voluntary, in making them we may not know what exactly we are committing ourselves to. Transforming unjust structures may require action that we do not anticipate and that we may not have intended to undertake at the outset. Yet we can continually endorse our commitments by standing by them, even when they take us in unexpected directions, and even as we are inevitably enmeshed in the relationships and obligations our commitments have generated.

Marin examines the substantive meaning of commitment through three examples of ways in which people are connected to - and therefore vulnerable to - each other: in the political and legal claims we make on each other; in the care we give and receive; and in the work we perform for and with one another.

Although laws are meant to limit our vulnerability to one other, they cannot eliminate it. We are connected to others because we are governed by the same laws; we are vulnerable to others because those common laws are open to varied degrees of interpretation, enforcement, and obedience, all of which require human judgment. The attempt to standardize such judgment is at the heart of Locke's social contract: human partiality renders judgment in the state of nature volatile, so people form a government in order to establish an impartial judge who can legitimately resolve conflicts. The establishment of such an authority, however, renders everyone vulnerable to their judgment, which is formalized into law. Marin argues that, instead of trying to limit judgment, we should understand it as inevitable and democratize it: anyone may question the judgment of the law, and act on their own judgment in order to remake it. In so doing, we ought to consider what kinds of relationships laws create: we owe allegiance to laws that create 'nonhierarchical social relations,' but not to those that do the reverse (p. 67). By obeying just laws and disobeying or changing unjust ones, we can affirm or reject our commitment to our shared legal-political structure.

The second example is that of intimate care, encompassing tasks from housework to child-minding. Everyone requires care throughout their life, and nearly everyone is capable of providing it - yet not everyone does. Although it is a form of labor, intimate care is separated from work because it occurs in the course of personal relationships and is subject to different norms than professional work. Marin discusses caregiving via marriage and family law. Following other feminist theorists, she argues that care is devalued because the skills it requires are unrecognized as such. Paramount among these is flexibility: good care requires a caregiver to spend a great deal of time paying attention to, assessing, and 
responding to other people's needs. But this amorphous and unpredictable work is not valued in a world of specialized tasks. Because caregivers spent time doing undervalued work instead of developing other skills, while those who receive care also receive time that they can spend on more highly valued activities, giving care opens one up to oppression. To combat this potential, Marin proposes a new form of marriage law that would grant caregivers greater rights and protections. Understanding marriage on the model of commitment, she argues, treats it as an open-ended relationship whose nature changes over time, and allows us to structure the rights that come with it accordingly.

Last comes work. Most people think of themselves as individual workers with distinct skills who make discrete contributions to society, and who merit the rewards that flow from that work. But we all rely on others to do some of the enormously complex work of making our society function, and we all rely on other people's skills in doing our own work. As paid work requires unpaid work, like that of intimate care, work designated as highly skilled cannot occur without work that is considered less skilled: each person's specialized abilities respond to and release those of others. A doctor cannot perform her work without the work of a nurse; neither can do their work without that of a janitor. Drawing on Thomas Piketty's account of inequality, Marin argues that the crucial class division 'in the current phase of capitalism' is not between workers doing 'high-skill' and 'low-skill' work, but between labor and capital (p. 123). The model of commitment helps us see work as something we necessarily do together instead of a set of competitive, specialized tasks; it can reveal the need for solidarity across different types of labor.

These substantive chapters are perceptive in their analysis of structural oppression and thoughtfully argued. But the discussion of commitment itself often feels shortchanged, and raises the question: is anything not best understood as commitment? Connection-by-commitment sometimes slips into a more diffuse, ultimately insubstantial notion of interdependence: in a global economy and planetary ecology, we are connected to just about everyone, and those connections come with obligations to act justly - although how these obligations vary with scale and distance is largely unaddressed. But commitment seems less a metaphor for connection, as Marin argues, than a descriptor of the action that follows from it. Labor, for example, may be a process of open-ended response to others' actions, but it does not necessary translate into any kind of political or collective action response to injustice: that is what the work of labor organizing does.

Yet, although Marin argues that 'only collective, long-term action can be transformative' (p. 19), explicitly political action appears only briefly, in the example of a protest. Instead, her examples deal primarily with relationships and situations that are not explicitly political. She is interested in the ways that structural oppression shapes our daily lives - the clothing we choose to wear, the ways we parent our children. As feminists have long observed, inequality and oppression are present in our most intimate practices and mundane patterns of

(c) 2018 Macmillan Publishers Ltd., part of Springer Nature. 1470-8914 Contemporary Political Theory Vol. 18, S3, S175-S178 S177 
action. Absent a more robust account of the specifically political nature of commitment, however, Marin risks the same difficulty that feminist declarations that the personal is political have long encountered: that the sites of politics become so diffuse as to disappear.

In fact, the notion of commitment quite precisely captures the nature of political organizing, which navigates between structural analysis and personal choices through the work of building relationships with others expressly in order to change unjust systems - relationships that in turn make new claims on us. It describes the everyday activity that lies beneath dramatic moments of political change, and the ongoing process of deciding to act in response to the recognition of our imbrication with others - and deciding to act again, and again, in open-ended and responsive ways that inevitably go beyond our intention and control. Such forms of political action remain undertheorized; political theorists would do well to draw on Marin's notion of commitment in developing them further.

\author{
Alyssa Battistoni \\ Yale University, New Haven, CT 06520, USA \\ alyssa.battistoni@yale.edu
}

